\title{
Social policy and embedded evaluation: Assessing the impact of a food insecurity project in the United Kingdom
}

DOI:

10.1111/spol.12583

\section{Document Version}

Accepted author manuscript

Link to publication record in Manchester Research Explorer

\section{Citation for published version (APA):}

Silver, D., \& Purdam, K. (2020). Social policy and embedded evaluation: Assessing the impact of a food insecurity project in the United Kingdom. Social Policy and Administration, 54(7), 999-1015.

https://doi.org/10.1111/spol.12583

\section{Published in:}

Social Policy and Administration

\section{Citing this paper}

Please note that where the full-text provided on Manchester Research Explorer is the Author Accepted Manuscript or Proof version this may differ from the final Published version. If citing, it is advised that you check and use the publisher's definitive version.

\section{General rights}

Copyright and moral rights for the publications made accessible in the Research Explorer are retained by the authors and/or other copyright owners and it is a condition of accessing publications that users recognise and abide by the legal requirements associated with these rights.

\section{Takedown policy}

If you believe that this document breaches copyright please refer to the University of Manchester's Takedown Procedures [http://man.ac.uk/04Y6Bo] or contact uml.scholarlycommunications@manchester.ac.uk providing relevant details, so we can investigate your claim.

\section{OPEN ACCESS}


Prepublication version - January 2020

Forthcoming in Social Policy and Administration

Social Policy and Embedded Evaluation - Assessing the Impact of a Food Insecurity Project in the UK

K. Purdam and D. Silver 


\title{
Social Policy and Embedded Evaluation - Assessing the Impact of a Food Insecurity Project in the UK
}

\begin{abstract}
Social policy-making needs to involve robust evaluation to assess its impact. In this article a social policy intervention focused on tackling food insecurity amongst vulnerable people is examined and the benefits and challenges of using an embedded approach to evaluation are considered. Food insecurity is defined as not always having the economic, social, and physical resources to ensure a sufficient supply of nutritionally appropriate food. Evidence suggests that food insecurity in the UK is increasing in the context of long term poverty, austerity, insecure employment, rising living costs, low pay and cuts to welfare and public services. An embedded evaluation was conducted involving: interviews with the intervention participants and observations of a series of cooking and food budgeting classes. The findings suggest that the classes had a positive impact on many of the participants, who felt more confident about cooking and valued the shared experience. However given the acute problems facing many of the participants including long term poverty, policies aimed at tackling food insecurity need to go beyond cooking and food budgeting skills. The embedded evaluation approach contributed towards the overall impact of the intervention by providing insights that led to changes as part of an iterative process during the intervention rather than in the form of a final report after its completion. An embedded evaluation based approach can be resource intensive and the role of the evaluators can present challenges, but it can help to bridge the gap between intervention design, delivery and social change.
\end{abstract}

Key Words: Austerity, Food Insecurity, Embedded Evaluation, Policy-Making, Poverty, Welfare Reform.

\section{INTRODUCTION}

In this article drawing on a case study of a food insecurity intervention aimed at supporting people in the UK living on low incomes develop their cooking and food budgeting skills an embedded evaluation approach is examined. The outcomes of the intervention and the benefits and challenges of using an embedded approach to evaluation are explored in detail.

Food insecurity is defined as not always having the economic, social, and physical resources to shop, cook, and eat in order to ensure a sufficient supply of nutritionally appropriate food (United Nations 2012). Evidence suggests that the prevalence of food insecurity in the UK is increasing (Garthwaite 2016). The Trussell Trust - the UK's largest foodbank network and the only such organisation to routinely monitor foodbank use - reported that their foodbanks had distributed more than 1.6 million parcels of emergency food in 2018 (Trussell Trust 2019). Moreover evidence suggests food insecurity is more widespread than just amongst those people relying on foodbanks (Purdam et al., 2015).

There is some debate about the causes of the rise in foodbank use in the UK but growing evidence suggests it is linked to long term poverty, austerity, insecure employment, rising living costs, low pay and cuts to welfare and public services (Caraher and Furey 2018; Lambie-Mumford and Green 2017; Loopstra et al., 2018, 2018; United Nations 2019). It is estimated that 4.7 million people in the UK live in persistent poverty (defined as experiencing relative low income both in the current year and at least two out of the three preceding years) (ONS 2019). The level of homelessness is also increasing (MHCLG 2019). Linked to these issues are debates 
about the impact of food literacy on food insecurity including food knowledge, planning and preparation skills (Begley et al., 2017, 2019; Foley and Pollard 1998; Pooler et al., 2017). The additional support needs some vulnerable people may have with shopping, preparing and eating food is also a concern (Purdam et al., 2019).

Social policy evaluation can be defined as the assessment of the impact of a targeted intervention to address a particular issue such as, for example, inequalities in education, employment and well-being (Fitzpatrick et al., 2004; Greve 2017; Mark et al., 2013). Effective evaluation is vital for the understanding of the impact on people's lives, to hold policy makers to account and to inform future policy decisions (Chelimsky 2013; Dahler-Larsen and Boodhoo 2019; Donaldson and Lipsey 2013; Greener and Greve 2013). Well-intended policy interventions can have unexpected and adverse impacts which need to be identified and addressed through robust evidence.

Evidence-based policy-making is a model of policy-making within which the introduction, continued delivery, adaptation or rejection of a policy depends upon the evidence produced during an evaluation (Duffy 2017; Oliver et al., 2014). Policy evaluation draws on different social research methods including, but not limited to, profile audits, baseline surveys, randomised controlled trials (RCTs) (where control groups are used), differential profiling and follow up interviews (Mark and Henry 2013). RCT based approaches can be used to capture individual level change and to try to identify the causal processes at work. However debates are ongoing about their strengths and limitations in different social policy contexts including, for example, in relation to the multidimensional nature of certain social policy interventions, the often complex life circumstances of vulnerable populations and the challenges and ethics in engaging hard to reach groups. RCT based approaches can include gathering more exploratory and in-depth qualitative data but this is not usually the primary aim (BIT 2018; Deeming 2013; Ettelt et al., 2015; John et al., 2011; Mark and Henry 2013; Richardson et al., 2019; Sunstein 2016). This issue is returned to in the Discussion section in relation to the case study cooking and food budgeting intervention.

There is considerable evidence concerning the methodological limitations of many social policy evaluations and how they can be used to justify political claims at the cost of the objective evaluation (Connelly and Vanderhoven 2018; Datta 2013; Greene 2013; Dahler-Larson 2017; Palfrey et al., 2012; Patton 2006; Vedung 2017; Vestman and Conner 2013). Back in the early 1970s Weiss (1973) argued that evaluation methods needed to improve if evaluation was going to contribute effectively to the process of policy learning. Some years later Weis (1993) highlighted how there were still ongoing challenges in the effective use of learning from evaluations.

In the UK the impact and the evaluation of the high-profile government Troubled Families programme has been questioned. The government claimed that the intervention, which initially targeted social support for 120,000 families living on low incomes and with complex problems, had a $100 \%$ success rate (DCLG 2015). However, the independent evaluation suggested that the impact in terms of increasing employment, improving health outcomes and reducing anti-social behaviour, was limited and questioned the robustness of the evaluation design and the data collected (Day et al., 2016; Parr and Churchill 2019). It is also notable that one of the key factors identified in the collapse of the high-profile UK children's charity Kids Company, which aimed to help children living in poverty, was a lack of robust internal or independent evaluation evidence to assess the impact and cost effectiveness of the outcomes of education and employment interventions (House of Commons 2016). Both of these social policy examples highlight the importance of robust evaluation methods and data. 
Embedded evaluation based approaches are where the evaluators are involved in the ongoing review and modification of an intervention as part of an iterative process. Such approaches have been used in aid programmes (Feinstein and Beck 2013). For example, the work of the UK government's Department for International Development includes the use of embedded evaluation (DFID 2013). ${ }^{\text {E }}$ Embedded evaluation also links with other approaches including: real time evaluation where evaluation takes place alongside the delivery of an intervention and contributes to operational change (Jamal and Crisp 2002); realist evaluation which highlights the importance of context and individual responses (Pawson and Tilley 1997); and coproduction based approaches, where participants are involved in the design and delivery of social policy interventions (Crompton 2019; Bevir et al., 2019; Richardson and Durose 2016).

This article examines the outcomes of a food insecurity intervention and considers the benefits and challenges of an embedded evaluation approach.

Key research questions: What were the impacts of an intervention aimed at tackling food insecurity using cooking and food budgeting skills training? In what ways did the intervention change with evidence from the embedded evaluation during its delivery? What were benefits and challenges of using an embedded approach for the participants, delivery organisations and the evaluators?

\section{BACKGROUND}

The effective evaluation of social policy interventions is a challenge. The UK National Audit Office, which scrutinises public spending, has identified considerable inconsistencies across government departments in terms of how policy evaluations are conducted and a lack of cross government evaluation (NAO 2013). The value of the evidence from social policy evaluations has also been questioned (Mathison 2018). Evaluations of social policy can be based upon outcomes that are predetermined and incentivized before the implementation of an intervention (Pearce and Raman 2014). A review of the UK government's Work Programme, which was designed to help people who were long term unemployed get back into work, identified how participants with less challenging issues were selected in order to meet payment by results targets (Carter and Whitworth 2016; Public Accounts Committee 2014).

Government departments in the UK are increasingly using experimental methods including RCTs to assess the impact of policy interventions (Haynes et al., 2013). This links to the government's focus on behaviour change based approaches. The Behavioural Insights Team (BIT) has used controlled trials of interventions including, for example, in relation to the payment of taxes, retirement planning and saving energy (BIT 2018). This approach has produced valuable evidence for evaluating policies and identifying what can work in terms of changing people's behaviour. However the approach has also been subject to some criticisms including in relation to the limited range of the policy areas it has been applied to, the need for more indepth understanding of the complexity of people's lives including those in vulnerable circumstances and long term poverty, the need for structural change alongside individual level change and the ethical issues raised by such approaches (Snowdon 2018).

In this challenging context it is important to explore more embedded approaches to evaluation where the participants, service organizations and evaluators are involved in developing the understanding of how the intervention is being delivered in a shared process of in-depth learning. Embedded evaluation based approaches involve a much more hands-on approach to evaluation with a focus on the views and experiences of participants as part of an iterative process. Such approaches to social 
policy evaluation link with action research, which involves a more democratic and participatory approach where there is the potential for producing knowledge that informs practice (Bradbury and Reason 2003; Brand et al., 2019; Coldwell 2019; Patton 2006). First hand evidence from participants can produce data that more accurately captures people's lived experience and is better able to identify what could lead to change in their lives (Causemann et al., 2013; Holland 2013; Richardson and Durose 2016; Schwandt and Burgon 2013). However, such approaches can be resource intensive and like any evaluation can raise questions about expertise, objectivity and ethics (Allen et al., 2019; Flinders et al., 2016).

In the methodology section below the cooking and food budgeting intervention and the approach to the evaluation are explained.

\section{METHODOLOGY}

\subsection{Cooking and Food Budgeting Classes}

The cooking and food budgeting case study intervention was designed to tackle food insecurity amongst vulnerable groups. Following good practice and informed by the Template for Intervention Description and Replication (TIDieR) framework (Hoffman et al., 2014) the details of the intervention are outlined below.

The aim of the intervention was to help participants develop their cooking and food budgeting skills and so help them reduce the risks of food insecurity. The project was a partnership between three foodbank charities, a homeless charity, and a food sharing charity. It was funded by a grant from the local city council.

The project ran for an 18-month period. In total 47 classes were held with 108 participants. The participants were recruited through the user groups of the different partner organizations and by advertising using local networks. All of the participants were living on low incomes either working part-time on zero hours contracts or relying on welfare benefits and many were living in temporary accommodation or were homeless. Each class involved around ten participants and lasted around two hours. The classes were held in four different locations and were led by a trained chef. Participants were able to attend as many sessions as they were able to in their local area. On average participants attended four classes during the time of the intervention. The classes involved the participants preparing and cooking fresh food and then eating together. Each participant was provided with ingredients and cooking equipment. Participants were also provided with information on cooking on a limited budget, recipe tips and advice for food budgeting.

The three foodbank charities, a homeless charity, and a food sharing charity were all involved in designing, coordinating and delivering the classes. The overall project was managed through a series of steering group meetings.

\subsection{Evaluation Approach}

An embedded approach to the evaluation was used which involved providing evidence to the project partners during the delivery of the intervention as part of an iterative process. The evaluation used a mixed method approach, combining the statistical strengths of quantitative data with insights gained from observations of the classes and informal discussions alongside life history interviews with the participants (Ayres 2008; Bryman 2015). In total the evaluators attended and contributed to five project steering group meetings, observed and participated in the cooking sessions across the four locations (including having informal conversations with the participants), semi-structured interviews with the 108 participants and postclass follow-up interviews with 61 of the participants and interviews with the five 
project partners. Finally, life history interviews were conducted with three participants in order to explore their individual circumstances and experiences in more depth.

\subsection{Data and Analysis}

(i) Observation and participation in cooking and food budgeting classes. One of the evaluation team attended the classes and joined in with other participants, cooking, talking and sharing food. Handwritten notes were taken. This enabled the collection of first hand reflections of how the classes were being run and the participant's experiences. The informal discussions covered such issues as engagement with the class and how the learning might be used in the future as well as more general issues about the delivery of the intervention.

(ii) Semi-structured interviews with the cooking and food budgeting class participants. The participants were recruited to the classes when visiting the foodbanks, through informal networks and through local advertising. Formal semistructured interviews with the participants were conducted before and after each class. The interviews were designed to explore the participants' individual experiences, their backgrounds, circumstances and their cooking and food budgeting skills. Each interview lasted around 30 minutes. Participation was voluntary and informed consent was obtained. In total, 108 interviews were conducted. The follow up interviews examined the participants' experiences in the classes. Overall, 61 follow up interviews were conducted. This data was used to assess the impact of the intervention at the individual and group level.

(iii) Life history interviews. Three life history interviews were conducted with people who had taken part in the classes. The life history approach invites participants to describe their life stories and experiences in their own words (Chamberlayne et al., 2002; Lune and Berg 2017). The interviews were exploratory without any set questions beyond asking the participants to talk about their lives and circumstances. Such biographical interviews can provide in-depth insights into the interplay between individual experiences and social and structural contexts without limiting the participant's responses with predetermined framing. The participants in the life history interviews were selected to represent the different circumstances and challenges the people were experiencing.

(iv) Informal discussions and interviews with the project delivery partners and data reporting. During the intervention informal discussions were held with the project partners and evidence was fed back. More formal interviews were also conducted with each of the five partner organisations in order to develop a deeper understanding of their perceptions of the how the classes were working and any changes that needed to be considered.

(v) Project steering group meetings - observation and participation. One of the research team attended all five project steering group meetings. The evaluators provided evidence on participation numbers, drop out rates and how the classes were being delivered from the experience of observing and participating and from the discussions and interviews with participants. The evidence was provided in the form of short update briefing reports and verbal feedback. In addition, during the steering group meetings, notes were also taken about the collaborative working between the project partners.

\subsection{Data Coding and Analysis}

The interview data collected from the participants before and after the cooking classes was entered into an SPSS database. The closed response questions were analysed using SPSS. The open response questions were analyzed using numerical coding in Word to identify the key issues and patterns emerging. The researchers 
cross coded the open response questions and then selected the quotes to highlight the key issues from the data.

The notes from the informal discussions, observations and life history interviews were also coded in relation to the different issues raised by the participants. The key themes emerging were then identified and again indicative quotes were selected to illustrate these themes.

\subsection{Fieldwork Context and Ethics}

The fieldwork context was a challenging one. Many of the interviewees were apprehensive about being interviewed. A number of the participants were living in vulnerable circumstances and it was not always possible to complete the full interview. If this was the case informal conversations were held and handwritten notes made. Comments were noted down verbatim.

Good practice guidelines were adhered to in relation to fieldwork safety and when conducting research with vulnerable groups (Iphofen and Tolich 2018). All the information collected was anonymised. The research was approved by the University's research ethics committee.

\section{FINDINGS}

The participants' experiences of being part of the cooking and food budgeting classes are first examined and then the benefits and challenges of the embedded approach to the evaluation are considered. The key themes identified from the multiple sources of evidence of the cooking and food budgeting classes include: the experiences of food insecurity, the development of skills, socializing and social eating, providing respite from everyday problems, confidence building and a sense of empowerment. The findings from the embedded evaluation include the changes made during the intervention such as in relation to the recruitment strategies, making the classes more supportive and participant led and the types of cooking. The benefits and challenges of the evaluation approach are also considered below.

\subsection{Part 1. The Impact of Cooking and Food Budgeting Classes}

\subsubsection{Food Insecurity}

All of the 108 participants were living on low incomes either working part-time on zero hours contracts or relying on welfare benefits, and many were reliant on food aid from foodbanks. Some participants were living in temporary accommodation including sleeping in night shelters or in women's hostels as a result of domestic abuse. One participant commented:

"I've been at my sister's, she has been making it easier, but it feels a little like begging and I don't like it." (Male, 58)

In terms of financial difficulties, $18 \%$ of participants had taken out a payday loan. $79 \%$ of participants reported that they had been skipping meals, often to enable their families to eat. As one participant in the life history interviews stated:

"There's been days when l've not ate, or I l've just been drinking coffee, to keep going. But I make sure my daughter eats." (Female, 48)

Participants also highlighted the strategies they were using to reduce their spending on food. One participant commented: 
"I work out when the lowest price stickers get put on in the supermarket, even at 9.30pm at night." (Female, 56)

Nearly two thirds of participants $(61 \%)$ reported asking for food from people they knew when they ran out usually from family or friends. However, other participants had stopped cooking and were putting their health at risk. As one participant commented:

"I drink a lot of milk - saves buying food because you don't eat as much." (Female, 58)

Many participants expressed concerns about unhealthy eating. Nearly half $(47 \%)$ of participants described their diet as 'very unhealthy' or 'fairly unhealthy'. Only $10 \%$ of participants felt that their diet was 'very healthy'.

\subsubsection{Coming to the Classes}

All of the participants stated that they were motivated to come to the classes. One participant commented:

"I want to learn more about cooking on a budget." (Female, 24)

For some participants attending the classes was about having something to do rather than the cooking training specifically. One of the life history interviewees described:

"I think it's nice to get into a different environment and come together to hopefully make some decent tasting food." (Male, 24)

Only just over a quarter of participants $(27 \%)$ had done any kind of course or training in the last year and $29 \%$ stated that they were anxious about taking part in the classes. As one participant explained:

"I was a bit anxious to start, now I am happy that I came." (Male, 18)

The majority of participants $(74 \%)$ stated that they knew other people on the cooking and food budgeting classes. This was a result of the local area focus of the classes. Knowing other people helped reduce peoples initial concerns about coming to the classes.

\subsubsection{Cooking and Cooking Skills}

Almost all of the participants (93\%) in the classes reported that they enjoyed cooking and most participants reported that they had some level of cooking skills with more than a third of participants (37\%) stating that they had 'Excellent cooking skills'. Most participants described how they had learnt their cooking skills from their parents or family. As one of the life history interviewees stated:

"I've always cooked for myself from a very young age. I mean, when I was seven or eight I was in the kitchen helping my mum cook dinner." (Female, 48)

Whilst many of the participants were cooking for themselves and their families, some were no longer cooking regularly as they had lost interest in cooking or did not have enough money to buy food. Often those participants living in temporary accommodation had no facilities for cooking. $26 \%$ of participants did not have an oven at home and $28 \%$ of participants did not have a fridge. As one participant stated:

“I need to get my own pots and pans." (Male, 53) 
The affordability of fresh ingredients was also an issue. $77 \%$ of participants stated that they could not afford to buy their 'first choice of food items'. $23 \%$ of participants also stated that they had difficulty getting to the shops due to travel costs and mobility issues.

\subsubsection{Cooking Skills Development - Follow-Up Interviews}

Follow-up interviews were conducted with the participants in order to examine their experiences and the impact of the cooking and food budgeting training. The key aspects participants valued about the classes included: learning new cooking skills, sharing their own skills, the information about sauces and spices, communal cooking and eating and the food budgeting tips.

In terms of the development of the participants' cooking skills $75 \%$ stated that after the classes they: 'Felt more confident about cooking healthily on a budget'. $72 \%$ of participants also stated that their confidence in cooking had either 'improved' or 'greatly improved'. As one participant commented:

"I learnt how to chop the proper way." (Male, 45)

Another participant described how:

"It was good to see how to combine new flavours." (Male, 20)

As an insight into assessing the appropriateness of the technical level of the intervention, $65 \%$ of participants stated that they had 'used ingredients which were new to them'. Overall, $65 \%$ of participants reported that they would 'eat more healthily', but $26 \%$ did not feel they would. A further challenge in terms of the success of the intervention was that $28 \%$ of participants felt that their confidence levels had 'stayed the same'.

Evidencing a potential longer-term impact of the intervention beyond cooking and food budgeting skills $84 \%$ of participants stated that they would 'cook the recipe again'. This could be seen as creating a new engagement with food and cooking. One of the participants described how cooking made her feel:

"It relieves stress and helps creativity come to life." (Female, 23)

Relatedly, another participant described how cooking gave her confidence:

“Cooking makes me feel independent." (Female, 42)

In addition, it is notable that $80 \%$ participants stated that they would share the skills they had learnt with family and friends, which suggests a potential wider impact of the intervention beyond the immediate participants.

\subsubsection{Additional Outcomes Beyond Cooking and Food Budgeting Skills}

The embedded evaluation also helped identify outcomes that went beyond the immediate aim of the intervention. These additional outcomes included: the importance of socialising, how the cooking classes provided a distraction from problems in the participants lives, confidence building and a sense of empowerment.

\section{Socialising and Social Eating}

The problems in the lives of the participants were not just about cooking and food budgeting skills. As one of the life history interviewees, who had explained their mental health problems, described in relation to the overall impact of the classes: 
"It's very therapeutic...the calming atmosphere, getting to have a laugh with people and you actually enjoy it and you know it. That was a meal that I just made, perfect." (Female, 22)

The emerging outcomes beyond improving cooking and food budgeting skills were evidenced from the embedded evaluation and the partner organisations were informed as the intervention was ongoing. More than had been expected, the classes served as a means for the participants to socialise, share recipes and cooking tips, and to eat together. The social and communal element of the classes was important including being out and meeting people. One participant highlighted the value of cooking together:

"I liked being part of the cooking group - nice to know other people's ways of cooking - everyone's tips and how they cook food differently." (Female, 59)

The collective aspect of learning, cooking together and sharing food was highly valued. As one participant stated:

"It was good to chat with other participants what their favourite veg was, how it is used and the things they use. It was nice to sit next to a chatty person." (Female, 28)

It is clear that many of the participants had not regularly been involved in such activities before. The value of sharing problems when cooking and eating with other people was also highlighted, as one participant commented:

"It is nice to talk to people... Nice to see different people and learn about the circumstances of others." (Female, 30)

Highlighting the social isolation many participants had been experiencing one participant commented:

"My hostel is awful. Sat in my room all day, it feels very lonely. I'm quite a sociable person." (Female, 26)

Describing their vulnerability and some of the challenges they faced one participant commented:

"Sometimes I lay in bed thinking that nobody cares about me. There is lots of anxiety and that makes me depressed. It has been nice being with people. Otherwise it gets lonely. I don't like being on my own." (Male, 48)

The role the classes were having in providing a distraction from the participants' everyday problems is considered in more detail below.

\section{An Escape From Everyday Problems}

In one of the life history interviews a female participant described how the cooking classes had provided a way for her to have a break from her daily problems:

"It's calming. It's a different atmosphere; you're actually learning things for your everyday life. Like you're learning something that's gonna help you in your life and basically help you to fend for yourself. Once you know what you're doing, you're just free and you can experiment." (Female, 22)

One of the participants also spoke about the classes being a 'sanctuary' and an escape from the challenges of their everyday life. She commented: 
"You can come in here and can get away from, the violence, the drug use the drinking, everything. When I cook, I mean, all the problems of the day go out the window." (Female, 30)

Some participants reflected on the ways in which coming to the cooking classes felt like they had some control and were making positive changes in their lives. One participant commented:

"It was like I was making a change to my life." (Male, 18)

Highlighting the impact on their own sense of self worth and confidence one participant stated:

"It made me feel useful." (Female, 21)

Perhaps most striking was the comment from one participant who was homeless who described how the class:

"Made me feel not homeless at all, for a minute." (Male, 26)

\section{Confidence Building and Sense of Empowerment}

The collective aspect of the cooking and eating was identified as an important outcome by the participants. One of the project partners commented on how the sense of being part of something was valued:

"There is great value in food, in feeding people. Also, I am big on relationships. This project has brought fellowship - people chatting, spending time with each other, bringing people together. There are people coming who are isolated, either within a community or on the edges of the community. This has improved people's confidence and interpersonal skills. I have seen people grow in confidence". (Female, project partner)

A notable aspect of the confidence building and sense of empowerment was that participants also cooked for other people. The classes cooked food for an evening night shelter, cooked for volunteer helpers from local businesses and helped run a food stall at a local festival. This event involved planning the menu and food costs, preparing the food and selling it to the public. Cooking for other people and other groups was not part of the original planned intervention, but was developed following ongoing discussions with the participants, the project partners and the evaluators. This also led to participants who were interested being signposted to more advanced food preparation and cooking courses at local colleges.

\subsection{Part 2. Embedded Evaluation}

\subsubsection{Intervention Changes}

In this section the benefits and the challenges of the embedded approach to evaluating the impact of the cooking and food budgeting classes intervention are examined. The embedded approach allowed evidence to be fed back to the project team through an iterative process of informal discussions via telephone calls and emails following each class, and more formally through interim reports to the project steering group.

Firstly, following feedback from the evaluation team during the second steering group meeting in month three of the intervention the recruitment strategy for the classes was revised. From this point on a more intensive campaign was put in place including using social media in order to ensure the classes and the overall project met the target for participant numbers. This also included reaching out to new groups within the local neighbourhoods, as participants had explained through informal 
conversations that it was not only people who used the foodbanks who were living in food insecurity.

Secondly, in month six of the intervention the format and content of the cooking and food budgeting classes were revised following observation and participation in the classes by the evaluators. One of the participants had commented:

"The trainer should let us cook, and do more, instead of chopping up vegetables and nothing much else. Let people try for themselves, because that's what cooking is." (Female, 41)

This participant's concern and similar concerns raised by other participants about the trainer's approach and the desire for more independent cooking was fed back to the project steering committee and to the trainers in the steering group meeting. This resulted in a more self-led approach to the cooking classes including encouraging participants to share their own skills and recipes. The remaining cooking classes were made more participatory in terms of ensuring engagement from participants who already had more advanced cooking skills. Some classes were adapted to take account of the limited cooking equipment some participants had at home. Given that some participants did not have access to any cooking equipment where they were living, there was also an increased focus on cooking food that could be taken away and eaten later. For example, some simple one-pot batch cooking recipes were introduced into the classes. This also contributed to the participants being able to take food home to share with family and friends.

Thirdly, the evaluation evidence was also fed back about the vulnerability of some participants and how they needed to feel more supported in the classes. Through documenting the everyday challenges participants faced as well understanding the participants' previous experiences of difficulties in their lives, the intervention was delivered with a more situated understanding of their lives. For example, a number of participants felt that the trainer was dismissive of their circumstances. These concerns were highlighted in one particular class that involved vulnerable women who were living in temporary accommodation. To begin with, this feedback was not received positively by all of the project partners; however, through evidence-informed discussion there was a constructive response and the classes were then delivered in a way that was supportive of participants who had different needs.

Fourthly, the embedded evaluation highlighted the importance of building the participants self-esteem and confidence. This had not previously been considered a key focus of the intervention but it became evident that building confidence would enhance both the delivery and potential outcomes of the cooking classes. It was therefore decided to address this in the subsequent classes. The adapted approach included encouraging participants to share their own skills with other participants and in the cooking of food for other people outside the classes including for charity volunteers and at a local festival as outlined above.

The other adaptations during the intervention resulting from the evidence provided by the participants and agreed during the project steering group meetings included: using a wider range of ingredients, the introduction of new recipes and food combinations, as well as enabling more skills and recipe sharing between participants. Participants were encouraged to share their skills and talk about the food they liked to cook and eat. These changes made the cooking classes more collaborative and engaging rather than being delivered by the trainer as a one-way process. The changes created a feeling of shared learning and enhanced the social aspect of the cooking classes, which participants had identified as important. It also helped some participants overcome the anxiety they felt, and provided them with a sense of empowerment from seeing the intervention change in response to their feedback. 
Finally, given the challenges many of the participants were facing, information on relevant frontline social and mental health services was provided. The contact details of support services including in relation to housing, health, welfare benefits and other food charities were made available in all of the classes as it became clear that many of the participants were not aware of all the support they could potentially access.

\subsubsection{Evaluation Challenges}

The embedded evaluation approach did however also raise some challenges. A key issue was the project partners' perceptions of the role of the evaluation and its independence. As explained above, the embedded evaluation was hands-on in terms of attending project steering group meetings, attending the cooking classes, and having informal conversations with the team members and the class participants. This raised some questions as to the purpose of the evaluation. This was particularly the case in the first few months of intervention in relation to the need to introduce new techniques for recruitment and in relation to ensuring that all the participants felt supported in the classes.

As outlined, feedback from the participants highlighted how they felt that the trainer could be more supportive of some participants and how the classes could be more participant-led. Feeding back this evidence was quite uncomfortable for the evaluators themselves as it related directly to the approach of trainers. It was important that the evaluators had support to discuss any challenges they encountered as a result of raising issues with the project partners. Another example was when a partner in the project expressed some concerns about what the evaluation might publish about the project. This partner was concerned about their reputation should the intervention not be evaluated as successful. As discussed below, it is important to ensure that all the partners in a project respect the independence of the embedded evaluation approach even when they might be dealing with critical feedback.

Finally, the evaluation was resource intensive in terms of the evaluator's time and required sustained involvement. For an embedded approach to be effective this needs to be fully costed into a project. Given the value of the evidence produced these costs can be considered good value in relation to both the immediate outcomes for the participants and in relation to informing policy decisions in the longer term. The issues raised by the embedded evaluation are discussed in more detail below.

\section{Discussion and Conclusions}

This article has examined the outcomes of a food insecurity intervention and considered the benefits and challenges of an embedded evaluation approach. The findings suggest that the classes had helped to re-engage the participants with food and cooking. The classes had a positive impact on their lives including feeling more confident about cooking having improved their skills and being able to take food home to share with family and friends. The participants gained confidence and a sense of empowerment from the experience of cooking and sharing food with others and also from cooking for other people outside of the classes. These activities helped reduce feelings of social isolation and provided a means for connecting with wider society in a positive way.

Moreover a potential future impact beyond the immediate intervention was how participants stated that they would share their skills with family and friends, although follow-up evidence would be needed to evaluate this. The cooking and food budgeting classes also served as a means for the participants to connect with other 
frontline services and support. This was particularly important for those participants who were homeless or vulnerably accommodated and who had very limited finances. In addition, some participants wanted to continue to develop their skills and were signposted to food preparation and cooking courses at local colleges.

The embedded approach to the evaluation aided the gathering of detailed evidence, which documented the underlying and often long-term daily challenges the participants were facing. As previous research has highlighted, tackling food insecurity needs to go beyond cooking and food budgeting classes and address long-term poverty, austerity, insecure employment, rising living costs, low pay and cuts to welfare and public services (Begley et al., 2019; Caraher and Davison 2019; Caraher and Furey 2018; Lambie-Mumford and Green 2017; Pollard and Booth 2019). The evaluation identified how the cooking and food budgeting issues were in many ways a consequence of the multiple difficulties the participants were facing. A more standard approach to an intervention and evaluation would have been unlikely to capture this important evidence.

The emerging evidence and the iterative process of the embedded evaluation informed the steering group's ongoing decision-making. This enabled any issues arising during the intervention to be addressed rapidly. As has been outlined, the changes included: putting additional resources into recruitment and ensuring that the trainer was more supportive in their approach. Recipes were also adjusted to take account of some of the needs of participants who had limited cooking equipment. Whilst these changes were small they contributed to the overall effective delivery of the intervention and positive change in the participants' lives. Outcomes were evidenced through the follow up interviews and through the informal discussions with the class participants. The participants gained a sense of empowerment as they saw how the changes to the intervention were made in response to their feedback.

The embedded evaluation also contributed to learning between the project partners during the steering group meetings. This was evidenced through the observation of the meetings where expertise and information were shared including, for example, in relation to developing the classes and also to other future projects and funding. The end of project feedback from the partners also suggests that they were considering using the embedded evaluation approach in future projects, potentially representing enhanced organisational learning that could impact beyond the immediate project. The evaluators themselves also gained insights into how social policy interventions and organisations use evidence in their decision-making processes and the challenges they can face. As such, it was also a learning process for the evaluators.

Embedded evaluation based approaches can be challenging. As with any evaluation questions can be raised about expertise and validity claims, objectivity and power relations (Allen et al., 2019; Crompton 2019). It is important that the independence of the process is protected. The role of the evaluator comes under close scrutiny, as they are present during the delivery of the intervention. The evaluators need to have the skills and experience required for such a challenging role and they need to be capable of providing constructive feedback, even when it is critical. It is vital that all the project partners are clear about the embedded nature of the evaluation from the start and understand that the evaluators will have ongoing input in the intervention.

Competing demands between project partners and any tensions between project partners also need to be addressed. For example, partners may have different views and resource demands arising from any issues that need addressing. In the cooking and food budgeting classes some trainers needed additional support because of the circumstances of some of the participants and this had to be agreed by all the project partners. There has to be a commitment by the project partners to accept the need for changes in response to ongoing evidence. Alongside formal steering group meetings communication channels should be open at all times to enable the 
discussion and assessment of emerging evidence and for the agreement of any adaptations to the delivery of the intervention in a collaborative way. Communication should take multiple forms including informal discussions as well as written reports. Whilst the written reports provide a formal record of the evidence and decisionmaking, the informal communication ensures that any issues are raised and considered quickly. For the cooking and food budgeting classes intervention a final evaluation report was written for internal use by the project partners and funders.

Finally, multiple types of evaluation data need to be collected to ensure that the evaluation is based on a range of perspectives that can contribute towards the iterative learning process when delivering an intervention. Embedded evaluation based approaches can therefore take considerable resources and require the evaluators to have a broad range of qualitative and quantitative research skills, for example, in relation to designing, collecting and analysing survey and interview data and in conducting informal discussions and observation based data gathering.

The need for more effective use of robust evidence in the development of social policy is becoming critical in the UK due to intractable social problems and also due to the impacts of austerity, cuts to public services and the need to be able to ensure that resources are allocated in more responsive and cost-effective ways (Beatty and Fothergill 2018; Hills 2015). Embedded evaluation based approaches can lead to more engaged and participatory social policy interventions and therefore more effective resource allocation in the longer term. They could be used as a means of initial feasibility studies and learning prior to the full testing of interventions including informing the design and delivery of RCT based approaches where appropriate. Embedded evaluation based approaches can help to bridge the gap between policy intervention design, delivery and social change, but challenges remain.

\section{Limitations}

The embedded evaluation explored in this study has limitations, which are in part linked to the wider challenges of social policy-making and evaluation with vulnerable populations. Firstly, the study was based on a single case study and there are limits as to what can be claimed beyond small-scale individual studies without a control group. A control group approach would potentially have enabled the identification of the impacts of the intervention more quantitatively. However, as outlined, given the exploratory nature of the cooking and food budgeting intervention and the vulnerable population involved an RCT based approach was not appropriate at this stage. Secondly, many of the participants in the classes were living in insecure and vulnerable circumstances including being homeless. This contributed to drop out in some of the classes. Again, this reflects the challenges of both delivering and evaluating social policy interventions with vulnerable populations.

\section{ACKNOWLEDGMENTS}

We would like to thank the participants and partner organisations for giving up their time to be interviewed. The research was supported by the University of Manchester and the Economic and Social Research Council.

\section{REFERENCES}

Allen, K., Needham, C., Hall, K. and Tanner, D. (2019). Participatory research meets validated outcome measures: Tensions in the co-production of social care evaluation. Social Policy Administration, 53: 311- 325.

Ayres, L. (2008). Semi-Structured Interview. In L.M. Given (eds) The SAGE

Encyclopedia of Qualitative Research Methods. London: Sage 810-812. 
Beatty, C. and Fothergill, S. (2018). Welfare reform in the UK 2010-16: Expectations, outcomes and local impacts. Social Policy \& Administration, 52 (5), 950-968.

Begley, A., Paynter, E., Butcher, L.M., and Dhaliwal, S.S. (2019). Examining the Association Between Food Literacy and Food Insecurity. Nutrients, 11, 445

Begley, A., Gallegos, D. and Vidgen, H. (2017), Effectiveness of Australian cooking skill interventions. British Food Journal, 119, (5), 973-991.

Bevir, M., Needham, C. and Waring, J. (2019). Inside co-production: ruling, resistance, and practice, Social Policy \& Administration. (On-line first).

BIT (2018). The Behavioural Insights Team. Annual Report. London: The Behavioural Insights Team.

Bradbury, H., and Reason, P. (2003). Action research: An opportunity for revitalizing research purpose and practices. Qualitative Social Work, 2, (2), 155-175.

Brand, S. L., Quinn, C., Pearson, M., Lennox, C., Owens, C., Kirkpatrick, T., Callaghan, L., Stirzaker, A., Michie, S., Maguire, M. Shaw, J. and Byng, R. (2019). Building programme theory to develop more adaptable and scalable complex interventions. Evaluation, 25, 2, 149-170.

Bryman, A. (2015). Social Research Methods. Oxford: Oxford University Press.

Caraher M. and Davison R. (2019). The normalisation of Food Aid: What happened to feeding people well? Emerald Open Research 1, (doi.org/10.12688/emeraldopenres.12842.1)

Caraher, M. and Furey, S. (2018). The Economics of Emergency Food Aid Provision: A Financial, Social and Cultural Perspective. London: Palgrave Macmillan.

Carter, E., and Whitworth, A. (2016). Work Activation Regimes and Well-being of Unemployed People: Rhetoric, Risk and Reality of Quasi-Marketization in the UK Work Programme. Social Policy \& Administration, 51, 796-816.

Causemann, B., Gohl, E., Rajathi, C. Susairaj, A., Tantry, G. and Tantry, S. (2013). In Holland, J. (Ed) Who Counts? The Power of Participatory Statistics. Rugby: Practical Action.

Chamberlayne, P., Rustin, M., and Wengraf, T. (Eds.). (2002). Biography and social exclusion in Europe: experiences and life journeys. Bristol: Policy Press.

Chelimsky, E. (2013). The Purposes of the Evaluation in Democratic Society. In Shaw, I.E., Greene, J.S. and Mark, M.M (eds) The Sage Handbook of Evaluation. London: Sage. 33-55.

Coldwell, M. (2019). Reconsidering context: Six underlying features of context to improve learning from evaluation. Evaluation, 25 (1), 99-117.

Connelly, S., and Vanderhoven, D. (2018). The Craft of Evaluative Practice: Negotiating Legitimate Methodologies Within Complex Interventions. Evaluation, 24, (4), 419-437.

Crompton, A. (2019). Inside co-production: Stakeholder meaning and situated practice. Social Policy \& Administration 53: 219-232. 
Dahler-Larsen, P. (2017). Critical Perspectives on using evidence in social policy. In Greve, B. (Ed.). Handbook of Social Policy Evaluation. Cheltenham: Edward Elgar Publishing. 242-262.

Dahler-Larsen, P., and Boodhoo, A. (2019). Evaluation culture and good governance: Is there a link? Evaluation. (On-line first, (doi.org/10.1177/1356389018819110).

Datta, L. (2013). The Practice of Evaluation: Challenges and Future Directions. In Shaw, I.E., Greene, J.S. and Mark, M.M (eds) The Sage Handbook of Evaluation. London: Sage. 419-438.

Day, L., Bryson, C., White, C., Purdon, S., Bewley, H., Kirchner Sala, L. and Portes, J. (2016). National Evaluation of the Troubled Families Programme Final Synthesis Report.

DCLG (2015). Troubled Families. London: Department for Communities and Local Government. London: Department for Communities and Local Government

Deeming, C. (2013). Trials and Tribulations: The 'Use' (and 'Misuse') of Evidence in Public Policy. Social Policy \& Administration, 47: 359-381.

DFID (2013). Evaluation Reports. London: Department for International Development.

Donaldson, S.I., and Lipsey, M.W. (2013). Roles for Theory in Contemporary Evaluation Practice: Developing Practical Knowledge. In Shaw, I.E., Greene, J.S. and Mark, M.M (eds) The Sage Handbook of Evaluation. London: Sage. 55-75.

Duffy, N.D. (2017). Evaluation and Governing in the 21st Century. London: Palgrave Macmillan.

Ettelt, S., Mays, N., and Allen, P. (2015). Policy experiments: Investigating effectiveness or confirming direction? Evaluation, 21, (3), 292-307.

Feinstein, O. and Beck, T. (2013). Evaluation of Development Interventions and Humanitarian Action. In Shaw, I.E., Greene, J.S. and Mark, M.M (eds) The Sage Handbook of Evaluation. London: Sage. 536-558.

Fitzpatrick, J., Sanders, J. R., and Worthen, B. R. (2004). Program Evaluation: Alternative Approaches and Practical Guidelines ( $3^{\text {rd }}$ ed.) Boston: Allyn \& Bacon.

Flinders, M., Wood, M. and Cunningham, M. (2016). The Politics of Co-production: Risks, Limits and Pollution. Evidence and Policy, 12, (2), 261-279.

Foley, R.M. and Pollard, C.M. (1998). Food Cent\$ - Implementing and evaluating a nutrition education project focusing on value for money. Australian and New Zealand Journal of Public Health, 22, (4), 494-501.

Garthwaite, K., (2016). Hunger pains: Life inside foodbank Britain. Bristol: Policy Press. 
Greene, J. C. (2013). Evaluation, Democracy and Social Change. In Shaw, I.E., Greene, J.S. and Mark, M.M (eds) The Sage Handbook of Evaluation. London: Sage. 118-140.

Greener, I. and Greve, B. (2013). Introduction: Evidence and Evaluation in Social Policy. Social Policy \& Administration, 47, 355-358.

Greve, B. (Ed.) (2017). Handbook of Social Policy Evaluation. Cheltenham: Edward Elgar Publishing.

Haynes, L., Service, O., Goldacre, B. and Torgerson, D. (2013). Developing Public Policy with Randomised Controlled Trials. London: Cabinet Office.

Hills, J. (2015). Good Times Bad Times. The Welfare Myth of Them and Us. London: Policy Press.

Hoffmann, C. T., Glasziou, P.P., Milne, R., Moher, D. et al. (2014). Better Reporting of Interventions: Template for Intervention Description and Replication (TIDieR) Checklist and Guide. British Medical Journal, 348, 1687.

Holland, J. (2013). Who Counts? The Power of Participatory Statistics. Rugby: Practical Action.

House of Commons (2016). The Collapse of Kids Company: Lessons for Charity Trustees, Professional Firms, the Charity Commission, and Whitehall. London: House of Commons HC433.

Iphofen, R. and Tolich, M. (2018). The SAGE Handbook of Qualitative Research Ethics. London: Sage.

Jamal, A. and Crisp, J. (2002). Real Time Humanitarian Evaluations. Geneva: United Nations High Commissioner For Refugees Evaluation And Policy Analysis Unit.

John, P., Cotterill, S., Moseley, A., Richardson, L., Smith, G., Stoker, G. and Wales, C. (2013). Nudge, Nudge, Think, Think: Experimenting with Ways to Change Civic Behaviour. London, Bloomsbury.

Lambie-Mumford, H. and Green, M. (2017). Austerity, Welfare Reform and the Rising Use of Foodbanks by Children in England and Wales. Area, 49, (3), 273-279.

Loopstra, R., Fledderjohann, J., Reeves, A., and Stuckler, D. (2018). Impact of Welfare Benefit Sanctioning on Food Insecurity: A Dynamic Cross-Area Study of Food Bank Usage in the UK. Journal of Social Policy, 47, (3), 437-457.

Lune, H. and Berg, B.L. (2017). Qualitative Research Methods for the Social Sciences. London: Pearson.

Mark, M.M. and Henry, G.T. (2013). Methods for Policy Making Knowledge Development Evaluations. In Shaw, I.E., Greene, J.S. and Mark, M.M (eds) The Sage Handbook of Evaluation. London: Sage. 317-339.

Mark, M.M., Greene, J.C. and Shaw, I.E. (2013). The Evaluation of Policies, Programs, and Practices. In Shaw, I.E., Greene, J.S. and Mark, M.M (eds) The Sage Handbook of Evaluation. London: Sage. 1-30. 
Mathison, S. (2018). Does evaluation contribute to the public good? Evaluation, 24 (1), 113-119.

MHCLG (2019). Statutory Homelessness. London: Ministry of Housing, Communities and Local Government.

National Audit Office. (2013). Evaluation in Government. London: HM Government

Oliver, K., Lorenc, T. and Innvær, S. (2014). New directions in evidence-based policy research: a critical analysis of the literature. Health Research Policy and Systems, 12. $12-34$.

ONS (2019). Persistent poverty in the UK and EU: Comparisons of persistent poverty between UK and other EU countries. London: Office for National Statistics.

Palfrey, C. Thomas, P. and Phillips, C. (2012) Evaluation for the Real World. The Impact of Evidence in Policy Making. Bristol: Policy Press.

Parr, S. and Churchill, H. (2019) The Troubled Families Programme: Learning about policy impact through realist case study research. Social Policy \& Administration, 114. https://doi.org/10.1111/spol.12529

Patton, M.Q. (2006). Evaluation for the Way We Work. The Nonprofit Quarterly, 13, (1), 28-33.

Pawson, R. and Tilley, N. (1997). Realistic Evaluation. London: Sage.

Pearce, W. and Raman, S. (2014). The New Randomised Controlled Trials (RCT) Movement in Public Policy: Challenges of Epistemic Governance. Policy Sciences 47, (4), 387-402.

Pollard, C.M. and Booth, S. (2019). Food Insecurity and Hunger in Rich Countries - It Is Time for Action against Inequality. International Journal of Environmental Research and Public Health, 16, (10), No. 1804.

Pooler, J.A., Morgan R.E., Wong, K., Wilkin, M.K. and Blitstein, J.L. (2017). Cooking Matters for Adults Improves Food Resource Management Skills and Self-confidence Among Low-Income Participants. Journal of Nutrition Education and Behaviour, 49, (7), 545-553.

Public Accounts Committee (2014). The Work Programme. London: House of Commons.

Purdam, K., Esmail, A. and Garratt, E. (2019). Food insecurity amongst older people in the UK. British Food Journal, 121, (3), 658-674.

Purdam, K., Garratt, E.A. and Esmail, A. (2015). Hungry? Food Insecurity, Social Stigma and Embarrassment in the UK. Sociology, 50, (6), 1072-1088.

Richardson, L., and Durose, C. (2016). Designing Public Policy for Co-production: theory, practice and change. Bristol: Policy Press/University of Chicago Press.

Richardson, L., Durose, C. and Perry, B. (2019). Moving towards hybridity in causal explanation: The example of citizen participation. Social Policy \& Administration, $53,265-278$. 
Schwandt, T. A. and Burgon, H. (2013). Evaluation and the Study of Lived Experience. In Shaw, I.E., Greene, J.S. and Mark, M.M (eds) The Sage Handbook of Evaluation. London: Sage. 98-117.

Snowdon, C. (2018). Paternalism, Nudging and Liberty. Economic Affairs, 38, 88-95.

Sunstein, C.R. (2016). The Ethics of Influence. Government in the Age of Behavioural Science. Cambridge: Cambridge University Press

Trussell Trust (2019). Foodbank Stats. Salisbury: Trussell Trust.

United Nations (2019). Visit to the United Kingdom of Great Britain and Northern Ireland. Report of the Special Rapporteur on Extreme Poverty and Human Rights. Geneva: United Nations.

United Nations (2012). Food Security and Nutrition. United Nations: New York, USA.

Vedung, E. (2017). Public Policy and Program Evaluation. London: Routledge.

Vestman, O. K., and Conner, R.F. (2013). The Relationship Between Evaluation and Politics. In Shaw, I.E., Greene, J.S. and Mark, M.M (eds) The Sage Handbook of Evaluation. London: Sage. 225-242.

Weiss, C. (1973). Where politics and evaluation research meet. Evaluation, 1(3), 3745.

Weiss, C. (1993). Politics and evaluation: a reprise with mellower overtones. Evaluation Practice, 14, (1), 93-106.

\footnotetext{
i See http://icai.independent.gov.uk/about-us/
} 